\title{
Study the Characterizations of Cement Mortar by Nano Pozzolanic Materials Additions
}

\author{
Fadhil A. Rasin* \\ Laith K. Abbas** \\ Mohammed J. Kadhim**** \\ *College of Sciencel University of Baghdad \\ **Department of Materials Engineering/University of Technology/Baghdad \\ ***Department of Materials Engineering/University of Mustansiriya/ Baghdad \\ **Email:Bestmoh111@yahoo.com \\ ***Email:moh_materials@yahoo.com
}

(Received 28 November 2016; accepted 12 April 2017)

https://doi.org/10.22153/kej.2017.06.004

\begin{abstract}
This study involves adding nano materials and interaction with cement mortar behavior for several mortar samples under variable curing time with constant water to cement ratio $(\mathrm{W} / \mathrm{C}=0.5)$. The effects of adding nano materials on the microstructure of cement mortar were studied by (Scanning Electronic Microscopy (SEM) and X-Ray) for samples at different curing time 28 and 91 days. Small ratio replacements of nano particles $\left(\mathrm{SiO}_{2}\right.$ or $\left.\mathrm{Al}_{2} \mathrm{O}_{3}\right)$ were added to Ordinary Portland Cement (OPC) type (I). The percentage of nano materials additives replacement by weight of ordinary Portland cement includes (1, 2, 3, 4 and 5\%) for both types of nano materials with constant (W/C) ratio, also the amount of the fine aggregate used was three times the amount of cement. The results showed that, the mortar consist of both nano materials had better microstructure than mortar without nano materials in all test. Best enhancements in properties and microstructure for mortars with nano silica were achieved with (3\%) additives while were achieved with nano alumina at $(2 \%)$ additives.
\end{abstract}

Keyword: Scanning Electronic Microscopy (SEM), X-Ray, nano- $\mathrm{Al}_{2} \mathrm{O}_{3}$, nano-SiO 2 .

\section{Introduction}

Nano technologies are being used in many applications especially in the field of constructions as building materials [1]. The large surface area of nano silica particles can be mainly be improved by pozzolanic property and effects filler on the cementitious matrix. [2] The micro structural and thermal analyses indicated that the shares of pozzolanic and filling effects on the pore structure refinement which depends on the percentage of nano silica addition [3]. The influences of nano silica particles, which its size is $(19 \mathrm{~nm})$ have been used as a cement addition by $(1,3,5,7$ and $10 \%)$ by weight of cement content. Scanning electron microscope (SEM) analysis of the microstructures showed that the nano silica filled the cement paste pores, also more homogeneity for cement paste and interfacial zone were created, this was done because of the reacting with calcium hydroxide crystals and the forming of more calcium silicate hydration [4]. Physical tests such as micro structure analysis by (SEM), identification of chemical composition by (X-Ray Fluorescent (XRF)), crystalline check for silica using (X-Ray Diffraction (XRF)) were performed on specimens contains (nano silica). The mechanical properties were achieved by performing strength tests for specimens in partial replacements such as $(5 \%, 10 \%$ and $15 \%)$ by weight of cement. From the results it was understood that cubes cast with (10\%) replacement of nano silica for cement by weight had better strength performance [5]. Experimental 
studies on adding (nano- $\mathrm{Fe}_{2} \mathrm{O}_{3}$ ) and (nano- $\mathrm{SiO}_{2}$ ) to cement mortars for the investigation of the cement mortars mechanical properties had been done. The (SEM) study of the microstructures between the cement mortar mixed with the nano particles and the control cement mortar showed that the (nano- $\mathrm{Fe}_{2} \mathrm{O}_{3}$ ) and (nano- $\mathrm{SiO}_{2}$ ) filled up the pores and decrease $\left(\mathrm{CaOH}_{2}\right)$ compound among the hydrates. These mechanisms explained the high mechanical performance of the cement mortars with nano particles [6]. Both mechanical and physical properties (permeability) of porous concrete containing (Nano-SiO 2 (PCNS)) were studied. Plain porous concrete (PPC) and porous concrete consists of (Micro-SiO 2 (PCMS)) have been studied as control materials. (28 day PCNS) results showed higher compressive and flexural strengths comparing to those of (plain porous concrete (PPC)) with the same water cement ratio $(\mathrm{W} / \mathrm{C})$. It was found that $\left(\mathrm{Nano}-\mathrm{SiO}_{2}(\mathrm{NS})\right)$ is better and effective than (Micro-SiO $\left.{ }_{2}(\mathrm{MS})\right)$ in enhancing (porous concrete (PC)) flexural strength. Samples with (5\% NS) by weight of binder presented the highest mechanical properties where the flexural and compressive strength of (porous concrete (PC)) were enhanced by (56\% and 48\%), respectively.[7] Mortars which are applicable for the casting of ferro cement elements reinforced with $\left(\right.$ nano- $\left.\mathrm{SiO}_{2}\right)$ particles were investigated. The mechanical properties of these mortars were studied and microstructural properties of interfacial transition zone (ITZ) by (Scanning Electron Microscopy and Atomic Force Microscopy tests). The mentioned tests specimens contain low replacement ratios of (nano- $\mathrm{SiO}_{2}$ ) particles $(1 \%, 2 \%$ and $3 \%$ ) were added to Ordinary Portland Cement (OPC) at water to binder ratio $(0.35,0.4$ and 0.5$)$ and sand to binder ratio (2:2.5). Results showed that (higher strength, low water absorption and denser (ITZ) properties were achieved) compared with the (OPC) ferro cement mortars that contains nano particles. Furthermore, increasing the (W/C), will lead to reduce the performance of silica nano particles [8]. Constant content of (Nano- $\mathrm{ZrO}_{2}$ (NZ), Nano--Fe $\mathrm{O}_{4}$ (NF), Nano $\mathrm{TiO}_{2}$ (NT) and Nano- $\mathrm{Al}_{2} \mathrm{O}_{3}$ (NA)) in another study have been added to concrete mixtures. Both, mechanical properties such as (compressive strength and indirect tensile strength) and physical properties such as (durability through chloride penetration test and concrete permeability) were investigated. Results showed an improvement in both mechanical properties and durability of concrete when nano particles added. Also, it was indicated that the $\left(\mathrm{Nano}-\mathrm{Al}_{2} \mathrm{O}_{3}\right)$ is the most effective nano particle of examined nano materials in the improvement of mechanical properties of high performance concrete [9]. At another study, waste ground ceramic was used and investigated as a pozzolan material in concrete with two different phases. Concrete samples with (10-40\%) of ground ceramic powder substitution were made. The currently effect of using $(0.5-1 \%)$ of (nano$\left.\mathrm{SiO}_{2}\right)$ and from (10\% to $\left.25 \%\right)$ of ground ceramic powder was determined. In all cases, compressive strength and water absorption tests were performed. Results showed that adding ground ceramic up to $(20 \%)$ does not have a significant effect on the concrete compressive strength. Furthermore, concrete water absorption capacity will be reduced by using waste ground ceramic. So, it can be figured that using (nano- $\mathrm{SiO}_{2}$ ) and pozzolan materials leads to improve compressive strength and decrease the capacity of water absorption. Therefore, the effects of ground ceramic powder on the properties of concrete can be improved by (nano-SiO${ }_{2}$ ) [10]. Two different types of (Nano silica (NS)) applied in selfcompacting concrete (SCC) was studied, both of them have similar particle size distributions (PSD), but produced through two different processes: fumed powder silica and deposition silica in colloidal suspension. The effect of (Nano silica) on (SCC) with respect to the properties of concrete in fresh (workability) and hardened state (mechanical properties and durability) were investigated. Hardened concrete microstructure has been verified and studied by (SEM) and (EDS) analyses. Results showed that (Nano silica) used in (SCC) improved the mechanical properties and durability of (SCC). Considering the reactivity of the two applied (Nano silica's), the type of colloidal have been showed a higher reactivity at early age, which enhance the final (SCC) properties [11]. The properties and the durability of (self-compacting concrete (SCC)) containing alginate in variety values with artificial stone resin, micro and nano silica were studied. The values of $(0.5$ and $1 \%)$ alginate, $(10 \%)$ micro silica, $(0.5 \%)$ nano silica and $(0.5 \%)$ artificial stone resin were used. Artificial stone resin was used as the super plasticizer. Properties of hardened (SCC) such as (compressive, split tensile, flexural strength and water absorption) were assessed and represented graphically. In general, the use of alginate improved the performance of (SCC) in fresh state and also avoided the use of viscosity modifying admixtures, adding nano silica to samples increased (SCC) and both (workability and the concrete split tensile strength) decreased in $(0.5 \%)$ 
alginate in all mixes receptacle $(0.5 \%)$ alginate. Results showed that adding micro silica to alginate increases the split tensile strength and adding nano and micro silica decreased the values of water absorption [12].

\section{Experimental Work}

\subsection{Materials}

There are many materials which are used to prepare specimens, these materials consist cement, fine aggregate, water and nano materials.

\subsection{Water}

The water is used for all physical tests and mortars specimens' preparation from mixing and curing stages and it was used for all the mechanical tests that had been carried out.

\subsection{Fine Aggregate}

Fine aggregates generally consist of natural sand or crushed stone with most particles smaller than $(5 \mathrm{~mm})$. Fine-aggregate grading within the limits of (ASTM C 33) is generally satisfactory for most concretes. The (ASTM C 33) limits with respect to sieve size. The sand used in this study is according to the standard specification after its sieved that has been used.

\subsection{Cement}

The type of cement was used for all mixes in this work is the Ordinary Portland cement (type I). The chemical analysis of the cement composition used is listed in Table (1). The cement concordance with the Iraqi specification (No.5/1984 ordinary Portland cement (type I)) from (Al Mass) Iraqi cement factory, the test in the table (1) was achieved in (National Centre for Construction Materials (NCCML) laboratory and research).
Table 1, The chemical composition of ordinary Portland cement (OPC).

\begin{tabular}{lll}
\hline $\begin{array}{l}\text { Oxides } \\
\text { Composition }\end{array}$ & $\begin{array}{l}\text { Oxide } \\
\text { content \% }\end{array}$ & $\begin{array}{l}\text { Limits of Iraqi } \\
\text { Specification } \\
\text { No.5/1984 }\end{array}$ \\
\hline $\mathrm{SiO}_{2}$ & $20.2^{7}$ & - \\
$\mathrm{Al}_{2} \mathrm{O}_{3}$ & 5.50 & - \\
$\mathrm{Fe}_{2} \mathrm{O}_{3}$ & 2.19 & - \\
$\mathrm{CaO}$ & $61 .{ }^{\mathrm{r}}$ & - \\
$\mathrm{MgO}$ & 1.99 & $<5.00$ \\
$\mathrm{SO}_{3}$ & 2.7 & $<2.8$ \\
$\mathrm{Free} \mathrm{CaO}$ & 1.12 & - \\
$\mathrm{Loss}$ on & 3.2 & $<4.00$ \\
Ignition & & $<1.50$ \\
Insoluble & 0.73 & \\
Residue & & $0.66-1.02$ \\
Lime \\
Saturation
\end{tabular}

\subsection{Nano Materials}

Two types of nano materials are used. The first type is nano-silica particles $\left(\mathrm{SiO}_{2}\right)$ and other type is nano-alumina particles $\left(\mathrm{Al}_{2} \mathrm{O}_{3}\right)$. Both have high purity approach to (99.9\%) and particle size rounded range between (15 to 20 nanometer). Nano Shell Company is the source of nano particles improved from the (Arrege Alfrat) Company.

\section{Preparation of Mortar Mixing}

The suitable mortar mixing was prepared by using cement sand ratio of $(1: 3)$ with $(\mathrm{W} / \mathrm{C})$ ratio of $(0.5 \%)$. Nano particles $(\mathrm{SiO} 2$ and $\mathrm{Al} 2 \mathrm{O} 3)$ were partially substituted in the (Ordinary Portland) cement and blended to create cement mortar samples. Electric mixer was used to assure complete homogeneity. The cement mortar specimens were molded into $(20 \mathrm{~mm})$ cubes for (SEM) tests and $(20 \mathrm{~mm})$ cubes for (XRD) tests. The specimens were remain in molds for (24) hours at $(100 \%)$ relative humidity and then immersed in water for $(3,7,14,21,28,60$ and 91 days).

\section{Microstructure Investigations 4.1. Scanning Electron Microscope (SEM)}

This test is achieved by using (TESCAN) by the device (VEGA SEM) in (Nano materials laboratory/Materials Engineering Department 
/College of Engineering /Al-Mustansiryiah University) and also was done in (Nano Materials Center in University of Technology). All samples must be prepared to an appropriate size to fit in the specimen chamber and are generally mounted rigidly on a specimen holder called a specimen stub. All samples must be coated by conductive materials in order to become conduction. Coating

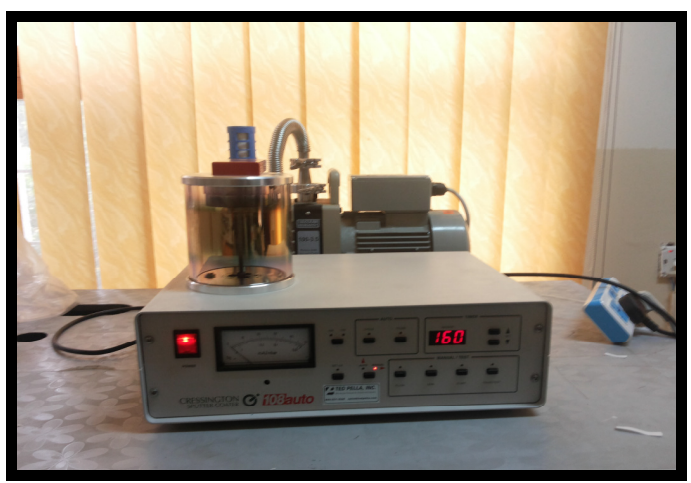

(a) process done by (Cressington (108)) Sputter Coaters. The sputter current is set on a digital program and is not dependent on the argon gas pressure in the sputtering chamber. Pressure adjustments and current adjustments are carried out separately. The (SEM) and sputter coater are shown in Figure (1).

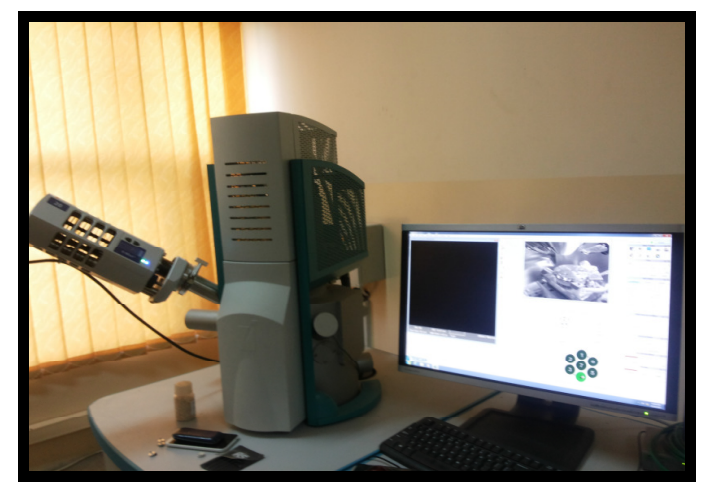

(b)

Fig. 1. (a) (Cressington 108) Sputter Coaters. (b) TESCAN Scanning Electron Microscope.

\subsection{X-Ray Diffraction (XRD)}

This test achieved by used (INEL diffractometer) in (Nano materials laboratory/Materials engineering department /college of engineering /Al-Mustansiryiah University). (INEL) instrument measure the entire

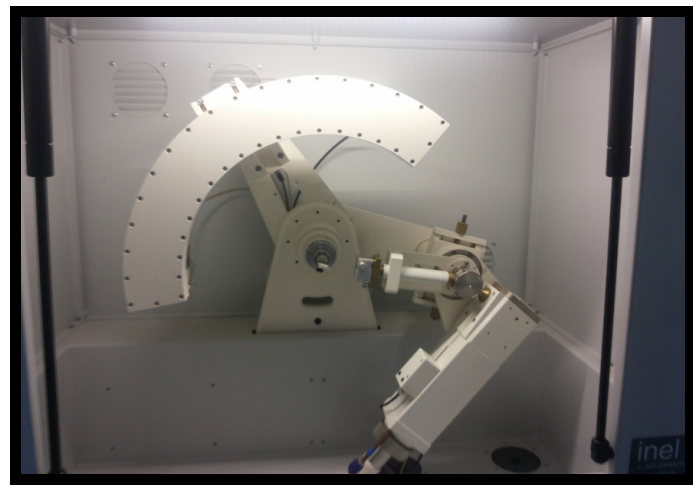

(a)
(20) diffraction angle pattern simultaneously by employ a unique curved (X-ray) detector. Crystallographic results are collected in a few seconds therefore analyzing a phase transition or unstable compound becomes possible. (INEL$\mathrm{XRD}$ ) device is shown in Figure (2).

Fig. 2. INEL (XRD) diffractometer. (a) The internal cabinet of (XRD) diffractometer. (b) The outer cabinet of (XRD) diffractometer with its chiller and its utilities.

\section{Result and Discussion}

One of a most importance tests to measure the localized microstructure mortar or concrete is (SEM) measurement. According to the (SEM) and (XRD) tests which indicate the results of the performance of nano particles in the interfacial transition zone (ITZ) between paste with and without nano materials and aggregate can be locally examined. The (SEM) micrographs of (OPC) cement powder is shown in Figure (3) and depending on the (XRD) test, the main components of cement powder are illustrated in Figure (4). These figures explains the main components of cement powder such as tricalcium 
silicate $\left(\mathrm{C}_{3} \mathrm{~S}\right)$, dicalcium silicate $\left(\mathrm{C}_{2} \mathrm{~S}\right)$ and the

calcium silicate hydration (C-S-H) gel reaction.

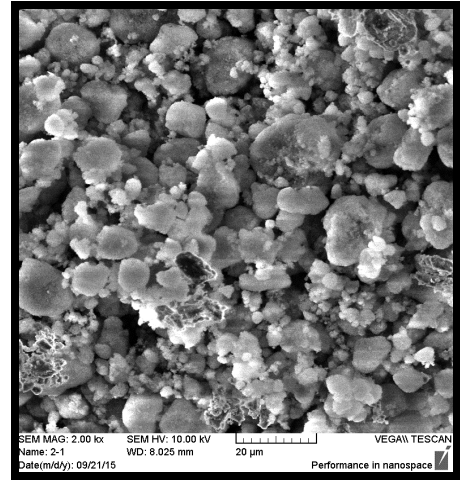

(a)

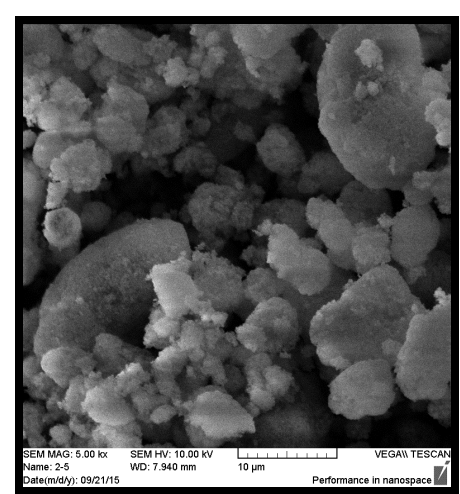

(b)

Fig. 3. SEM photomicrographs of the cement powder microstructure at low vacuum (0.7 mbar).

Figure (5-a) shows the microstructure of pure nano silica powder and according to (X-Ray) measurement the purity of nano silica $\left(\mathrm{SiO}_{2}\right)$ powder shown in figure (5-b), and microstructure of nano Alumina $\left(\mathrm{Al}_{2} \mathrm{O}_{3}\right)$ shown in figure (6-a) and the purity of nano alumina is illustrated in
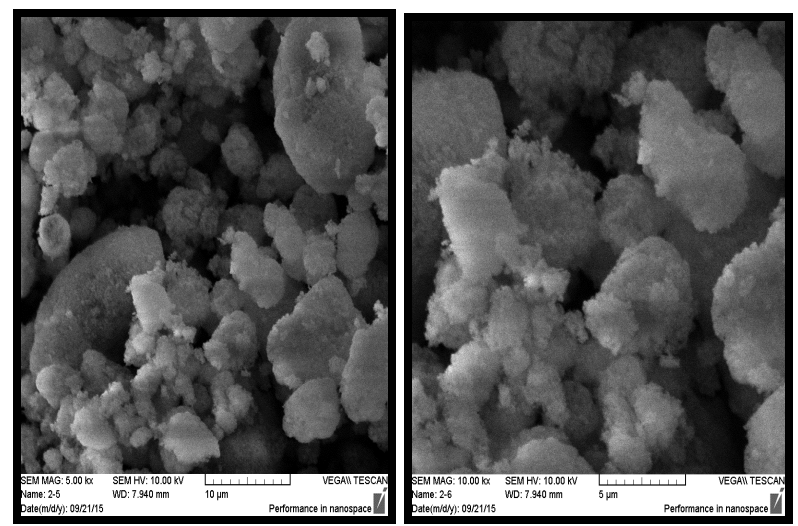

(a) figure (6-b). The microstructure of control cement mortar without nano particles addition is shown in figure (7-a) at (28 days), figure (7-b) is for the (91 days) of curing and the main components of hydrations reaction are observed in figure (7-c).

Fig. 4. The characterization measurement Microstructure at low vacuum (0.7 mbar) (a) SEM, (b) (XRD) pattern of (Ordinary Portland Cement (OPC)) powder.
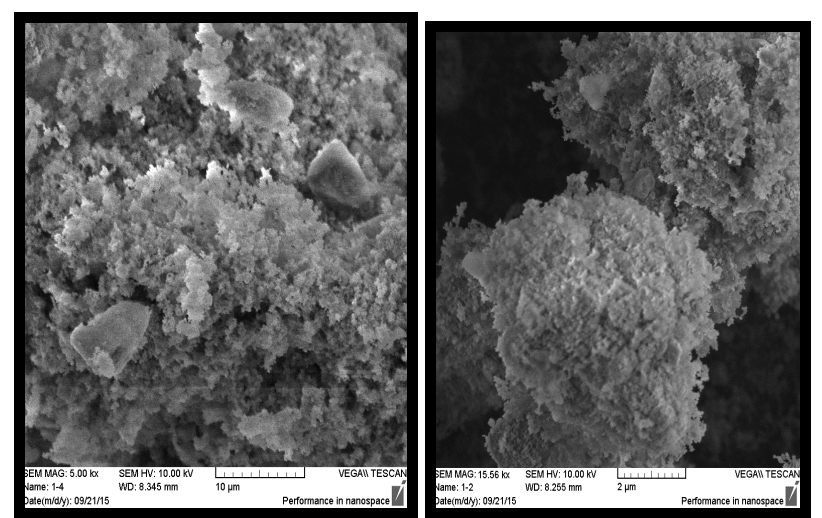

(a)

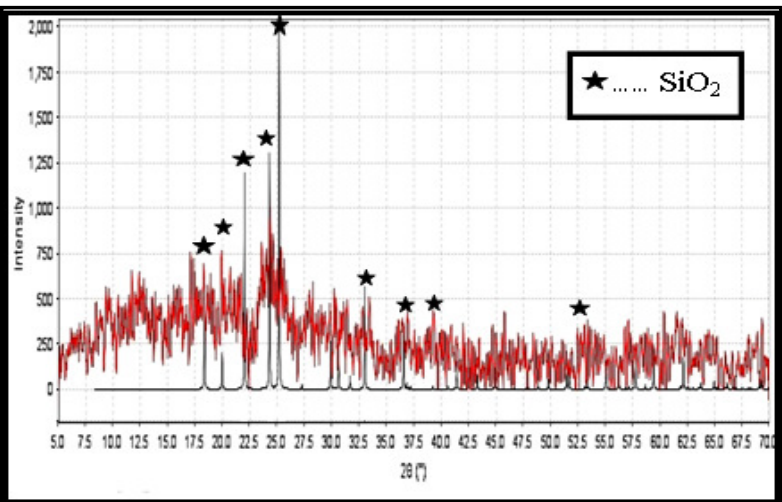

(b)

Fig. 5. The characterization measurement (a) (SEM) and (b) (XRD) pattern of pure nano silica $\left(\mathrm{SiO}_{2}\right)$ powder. 
The microstructure of control mortar of cement at (28 and 91) days can be illustrate in figure (7-a) and (7-b) which shows the microstructure of cement mortar during the hydrations process at the (4 weeks) and (12 weeks) from curing time.
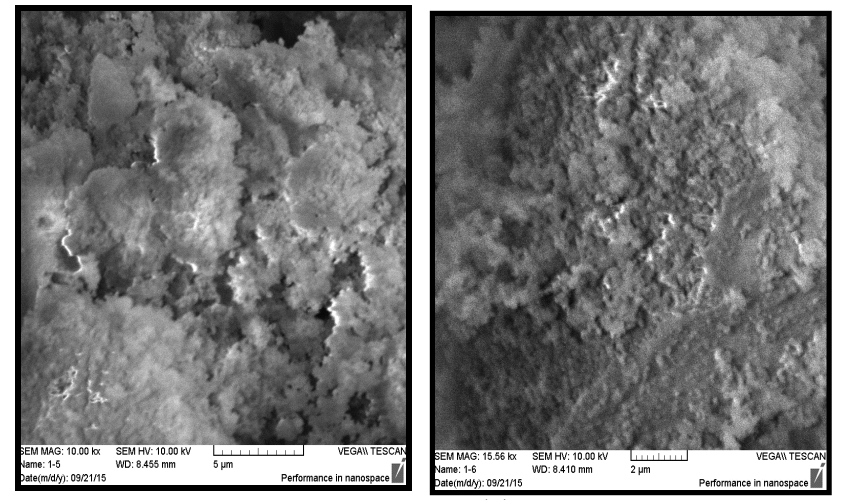

(a)

Fig. 6. The characterization measurement (a) (SEM), (b)

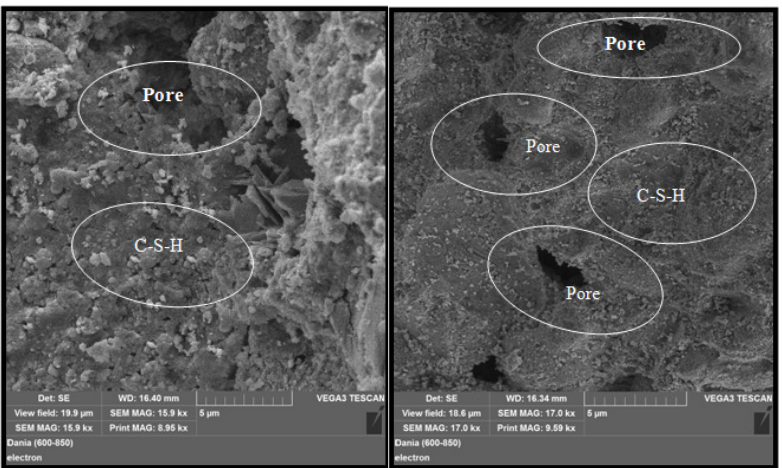

(a)

(b)

Fig. 7. The characterization measurement (SEM) (a) at (28 days) and (b) at (91 days), (c) (XRD) pattern of control mortar without nano materials.

The effects of nano alumina $\left(\mathrm{Al}_{2} \mathrm{O}_{3}\right)$ at $(1 \%)$ ratio on the microstructure can be considered as controlling the hydrations reaction, the nano particles begin to appear as a white paint in the substrate of cement mortar, this can be seen in figure (8-a), but this paint begin to decrease with time increase at ((91 days) curing) which can be observed in figure (8-b). The capacity of filling process, activity of pozzolanic reactions and the hydration rate of the cement will decrease, the porosity and the nano materials begin to penetrate in the materials which become denser than control specimen, the main component can be illustrate in figure (8-c).

Specimens microstructure with (1\%) nano silica $\left(\mathrm{SiO}_{2}\right)$ had a substrate materials consist of nano- $\mathrm{SiO}_{2}$ particles which was clearly appeared (at 28 days), this can be illustrated in figure (9-a), then the microstructure developed more and distribution of nano silica particles begin to hide
The main components of control specimens that had been formed during the variation of curing time can be shown in figure (7-c) for control specimens at varying curing time.

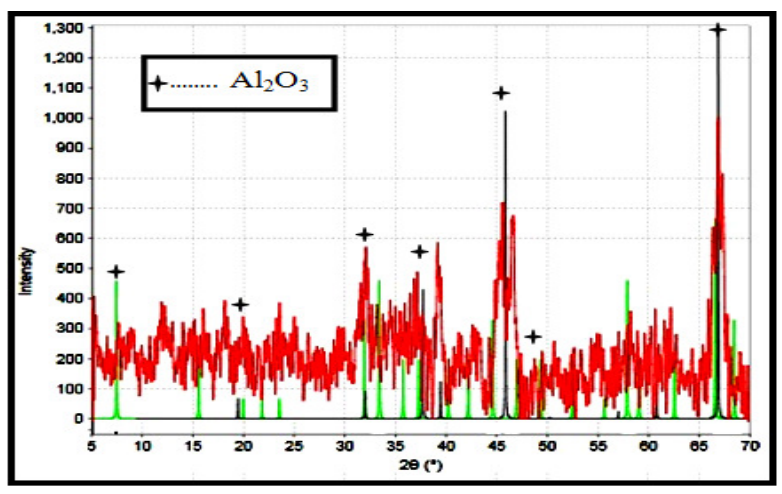

(b)

(XRD) pattern of pure nano alumina $\left(\mathrm{AL}_{2} \mathrm{O}_{3}\right)$ powder.

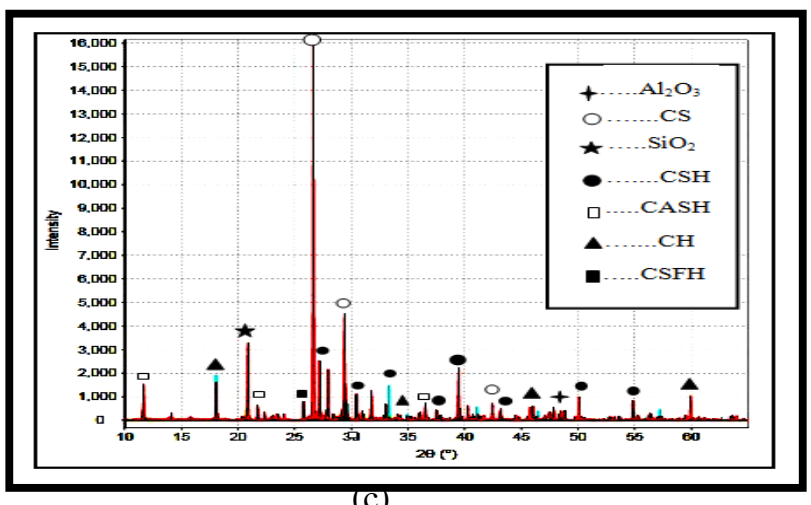
when the curing time increase, this can be observed in figure (9-b) this was happened because the materials have pozzolanic activity and filling the pores between particles, the main phases component during the hydrations reaction can be shown in figure (9-c).

When adding of nano alumina (nano- $\mathrm{Al}_{2} \mathrm{O}_{3}$ ) replacement reach to $(2 \%)$, the microstructure of mortar with nano addition begin to give better nucleation and the (C-S-H) gel begin to form and the phase $\left(\mathrm{Ca}(\mathrm{OH})_{2}\right)$ began to decrease compared with control specimens, this microstructure improved the mechanical properties. The micro structure of (2\%) nano alumina replacement addition can be seen in figure (10-a) for (28 days) and (10-b) for (91 days). Basically the enhancement in microstructure depends on the packing effect of filling the voids that created during the hydration reactions and the mortar become denser. The main component during the 
hydrations process can by illustrate by the (XRD) measurement in figure $(10-c)$. Because the amount of nano particles were increased more than (2\%) the agglomeration were formed. When the amount of nano alumina increase up to $(5 \%)$ the voids

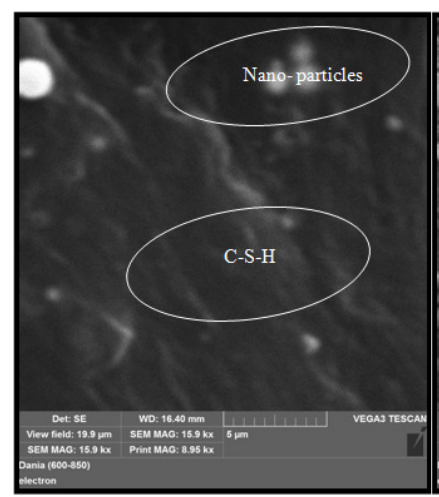

(a)

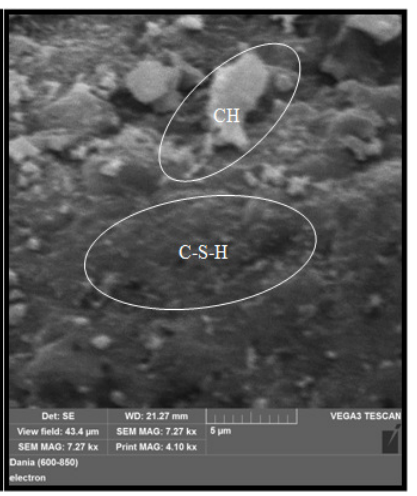

(b) begin to increase more at the percent $(3,4$ and $5 \%$ ) according to figure $(11,12$ and 13$)$ which are explains the effect of nano alumina more than (2\%) replacement addition.

Fig. 8. The characterization measurement (SEM) (a) at (28 days) and (b) at (91 days), (c) (XRD) pattern of mortar consist $\left(1 \% \mathrm{AL}_{2} \mathrm{O}_{3}\right)$ nano materials sample.

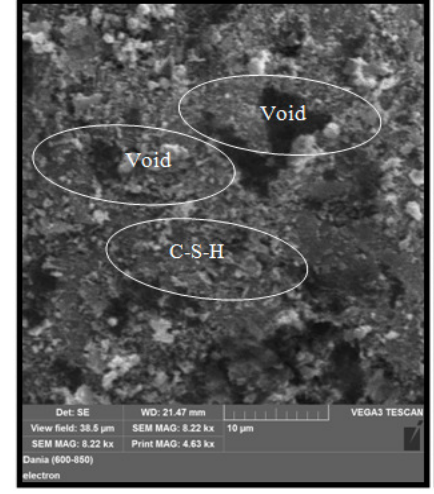

(a)

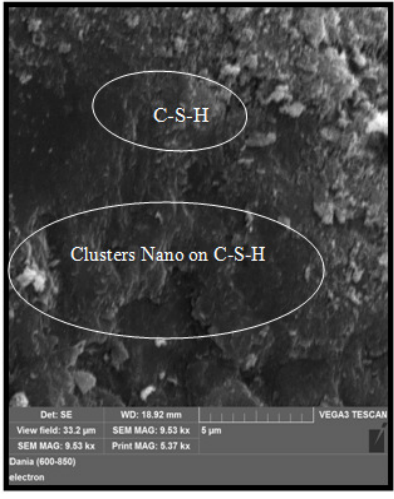

(b)

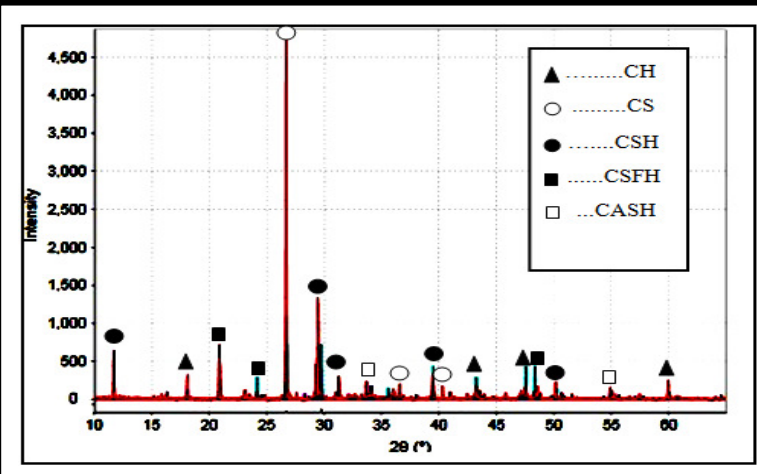

(c)

Fig. 9. The characterization measurement (SEM) (a) at (28 days) and (b) at (91 days), (c) (XRD) pattern of mortar consist (1\% SiO2) nano materials sample.

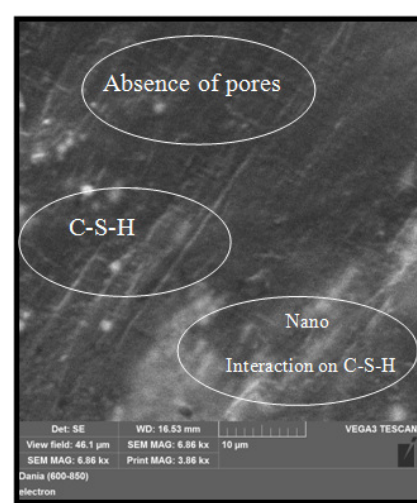

(a)

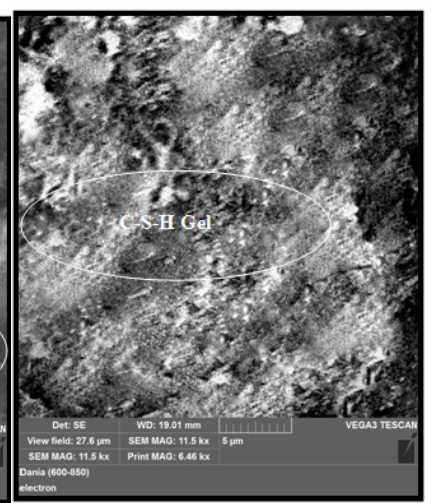

(b)

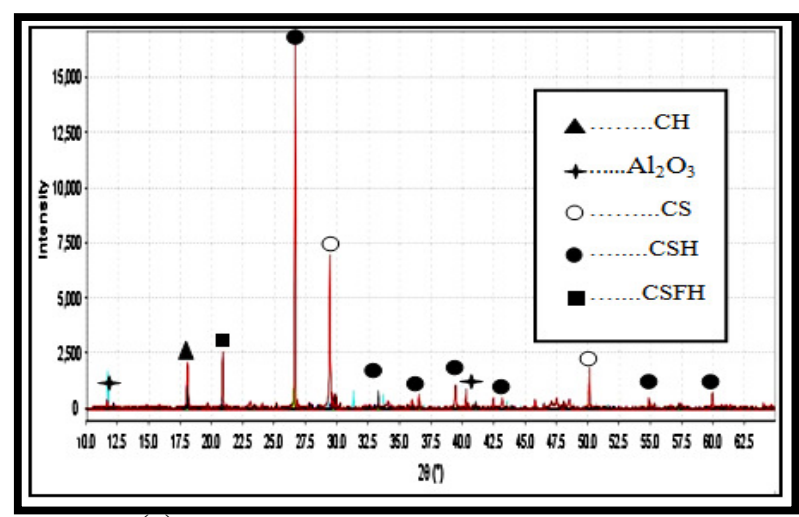

(c)

Fig. 10. The characterization measurement (SEM) (a) at (28 days) and (b) at (91 days), (c) (XRD) pattern of mortar consist (2\% AL2O3) nano materials sample. 


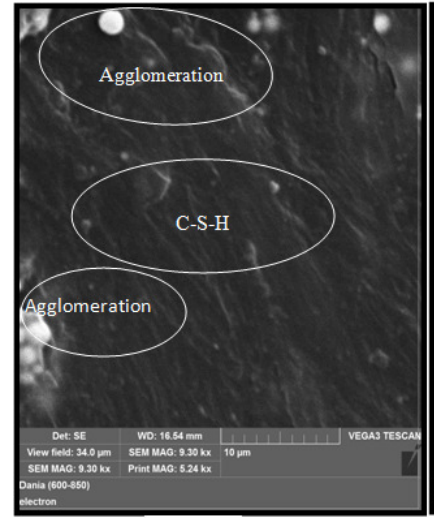

(a)

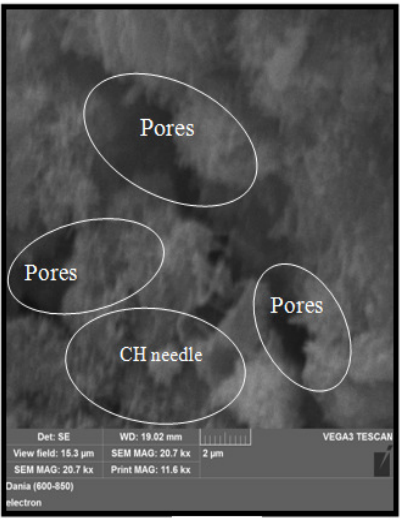

(b)

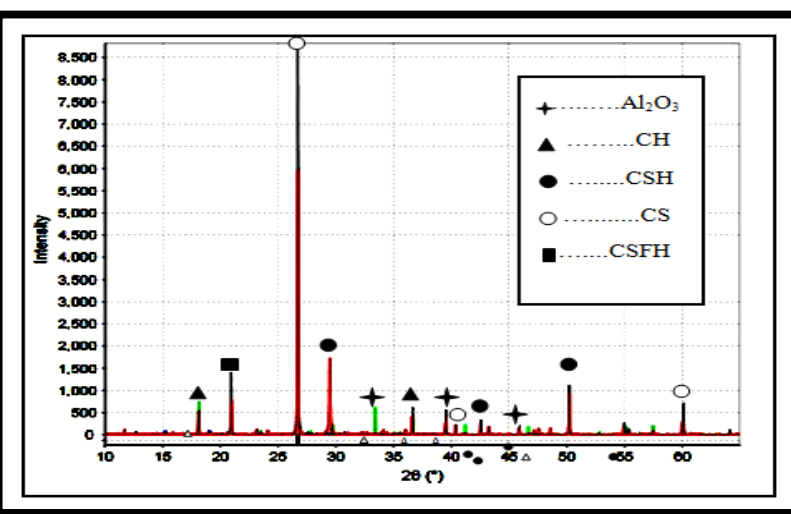

(c)

Fig. 11. The characterization measurement (SEM) (a) at (28 days) and (b) at (91 days), (c) (XRD) pattern of mortar consist $\left(3 \% \mathrm{AL}_{2} \mathrm{O}_{3}\right)$ nano materials sample.

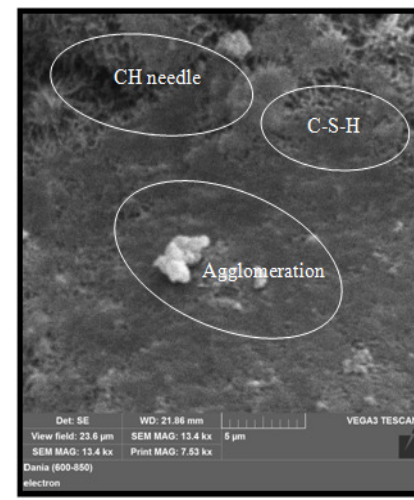

(a)

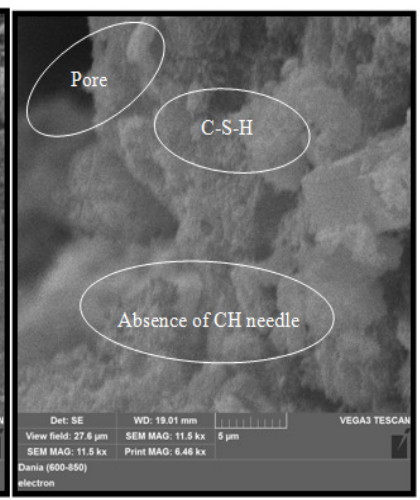

(b)

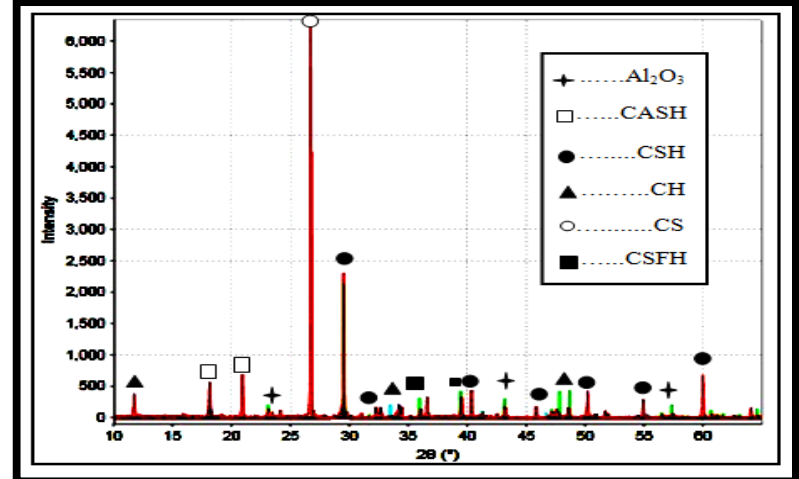

(c)

Fig. 12. The characterization measurement (SEM) (a) at (28 days) and (b) at (91 days), (c) (XRD) pattern of mortar consist (4\% AL2O3) nano materials sample.

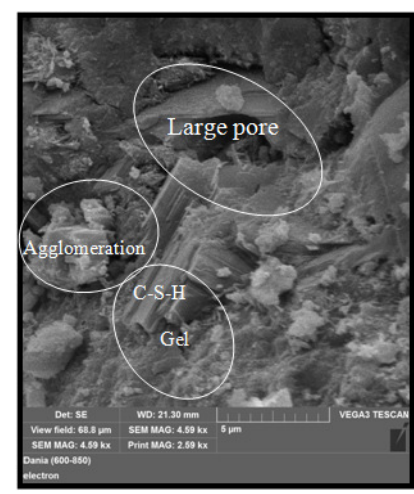

(a)

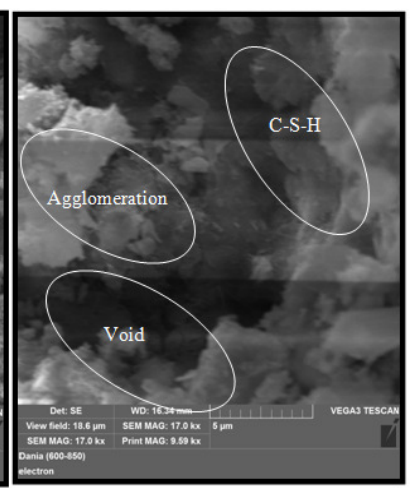

(b)

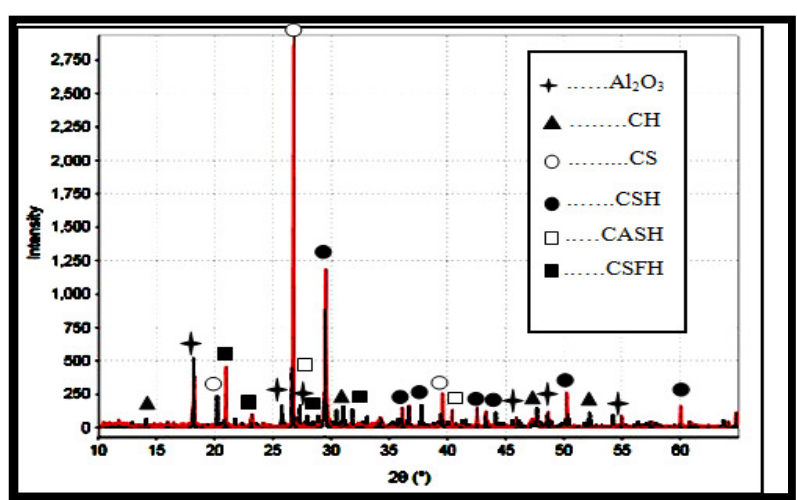

(c)

Fig. 13. The characterization measurement (SEM) (a) at (28 days) and (b) at (91 days), (c) (XRD) pattern of mortar consist (5\% AL2O3) nano materials sample.

The microstructure of the mortar developed when the replacement addition of nano silica $\left(\mathrm{SiO}_{2}\right)$ reaches $(2 \%)$ and enhancement in this microstructure achieved, this behave can be observed in figure (14-a) for (28 day) and (91 day) illustrate in figure (14-b), the main components (phases) during cuing time can be showed in figure (14-c). 


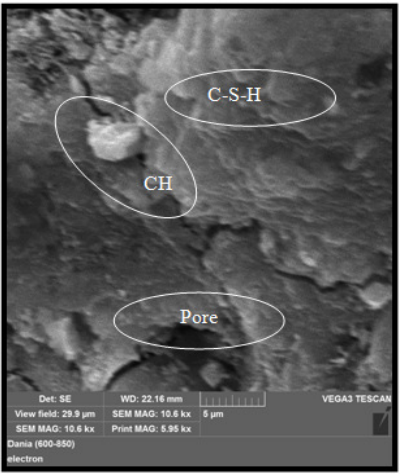

(a)

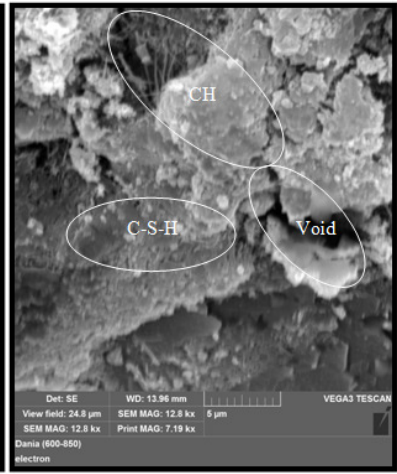

(b)

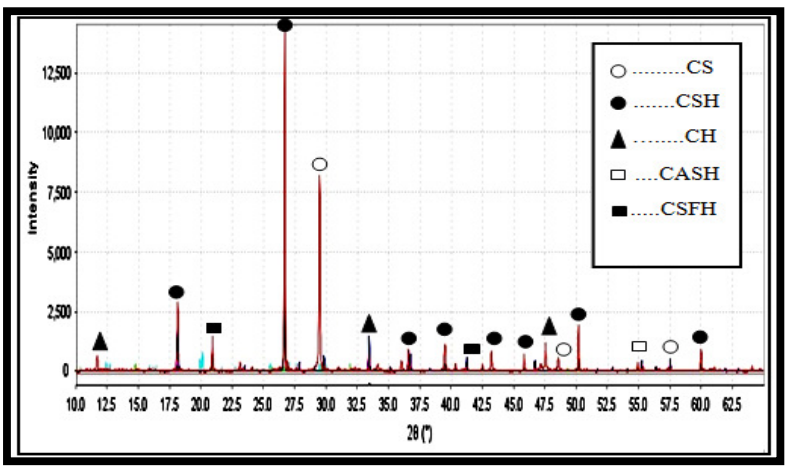

(c)

Fig. 14. The characterization measurement (SEM) (a) at (28 days) and (b) at (91 days), (c) (XRD) pattern of mortar consist $(2 \% \mathrm{SiO2})$ nano materials sample.

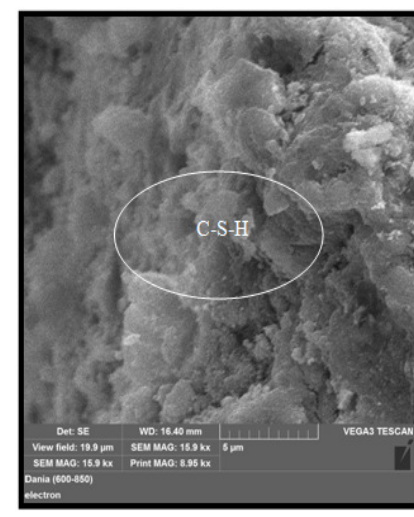

(a)

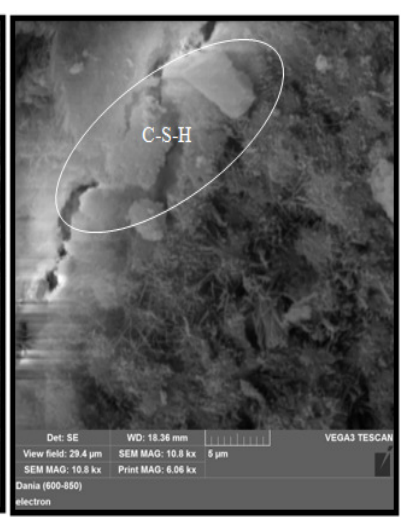

(b)

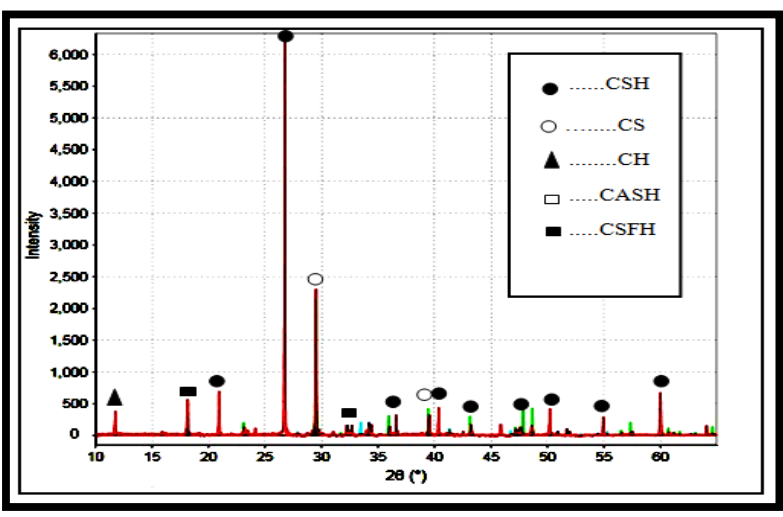

(c)

Fig. 15. The characterization measurement (SEM) (a) at (28 days) and (b) at (91 days), (c) (XRD) pattern of mortar consist $\left(3 \% \mathrm{SiO}_{2}\right)$ nano materials sample.

Mortar with increasing the amount of (nano$\mathrm{SiO}_{2}$ ) until reaches to the percentage (3\%) is denser and more homogenous than the control samples of cement mortar, this can be seen clearly in the (SEM) of mortar microstructure which is shown in figure (15-a) for 28 days and 15-b) for 91 day. This is happened because of the pozzolanic reaction by consumption of $\left(\mathrm{Ca}(\mathrm{OH})_{2}\right)$ and the formation of additional (C-S-H) gel, that lead to improve the microstructure of mortar which as a result fill the pores system and causing densification effect, which fill the pores system. The main component during the hydrations process can be observed in figure (15-c).
With the increase of nano silica $\left(\mathrm{SiO}_{2}\right)$ particles quantity up to (3\%), microstructure was improved completely and achieved better density. Usage of more amount of nano silica particles reach to $(3 \%)$ will lead to make the cement paste matrix denser in a way that remarkable permeability reduction has been observed. So, the pozzolanic performance of silica nano particles is shown clearly in the case of mortar durability. It was found that samples containing nano silica $\left(\mathrm{SiO}_{2}\right)$ particles and because of the agglomeration voids were created. Figures (16) and figure (17) illustrate the behavior at (4 and 5\%) nano silica $\left(\mathrm{SiO}_{2}\right)$ particles additions. 


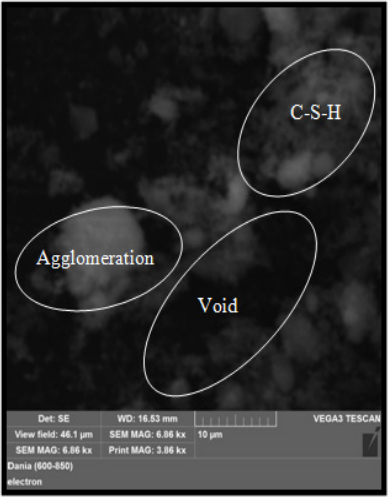

(a)

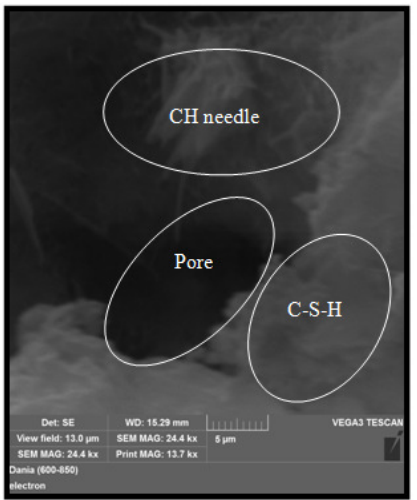

(b)

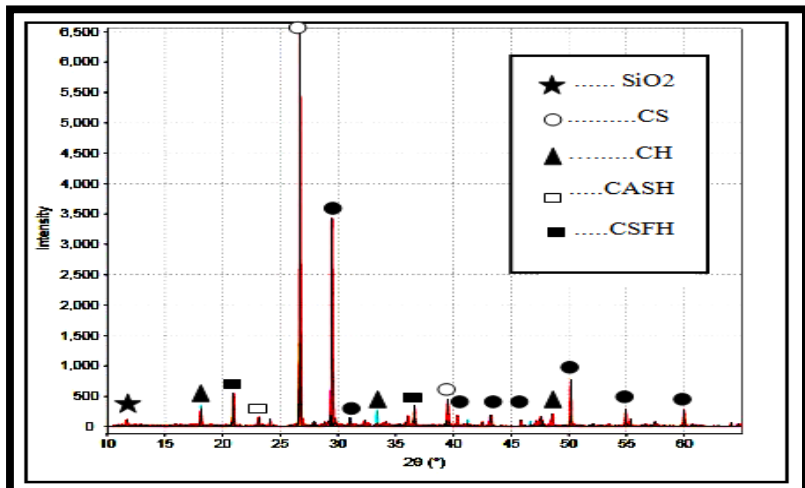

(c)

Fig. 16. The characterization measurement (SEM) (a) at (28 days) and (b) at (91 days), (c) (XRD) pattern of mortar consist $\left(4 \% \mathrm{SiO}_{2}\right)$ nano materials sample.

However, when the particles of nano silica don't dispersed well, as in condition of widening content of nano particles, the agglomeration will be produced and create a defective area in a form

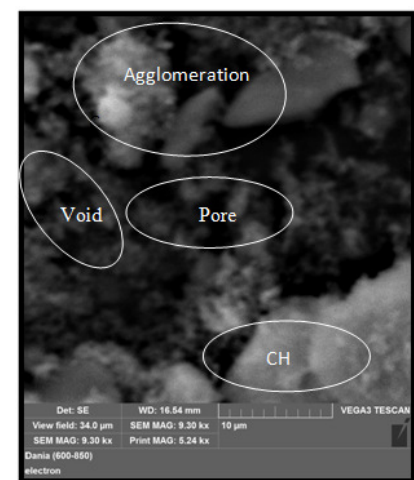

(a)

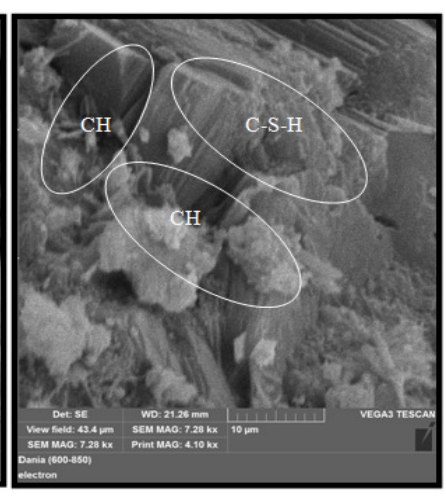

(b) of consequently voids. So, the homogeneous structure during process of hydration will not be formed and also low strength will be expected.

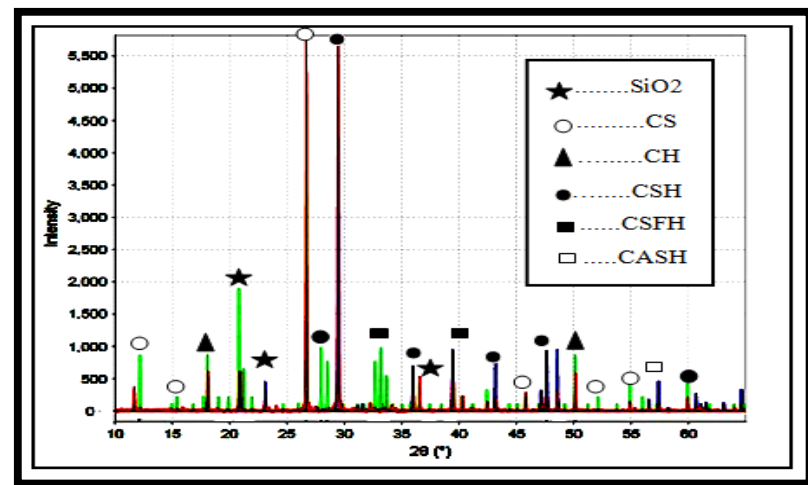

(c)

Fig. 17. The characterization measurement (SEM) (a) at (28 days) and (b) at (91 days), (c) (XRD) pattern of mortar consist $\left(5 \% \mathrm{SiO}_{2}\right)$ nano materials sample.

\section{Conclusions}

According to the results from the experimental results following points can be concluded:

1. The collection of various sizes of (nano additives) reduces the total volume of voids between aggregates.

2. From Scanning electron microscopy (SEM) the (nano-Al2O3) and (nano-SiO2) particles fill the pores and also reduce the content of $(\mathrm{Ca}(\mathrm{OH}) 2)$ within the hydration products.

3. Nano-(SiO2) participates in the pozzolanic reactions, resulting in the consumption of $(\mathrm{Ca}(\mathrm{OH}) 2)$ and formation of an additional $(\mathrm{C}-$ $\mathrm{S}-\mathrm{H})$ gel.

4. Well dispersed nano particles act as centers of crystallization of cement hydrates, therefore accelerating the hydration.
5. The microstructure of mortar consist of nano silica is more homogeneous than mortar containing the same replacement of nano alumina at all curing ages.

6. The workability of mortar will be decrease when the ratio amount of nano silica and nano alumina replacement increased compared with control mortar.

7. Optimum nano alumina replacement ratio that improved the microstructure at (28 days) and (91 days) compared with control mortar is $2 \%$.

8. Optimum nano silica replacement ratio that improved the microstructure at (28 days) and (91 days) compared with control mortar is $3 \%$. 


\section{Refrences}

[1] A.Boshehrian1, P.Hosseini, "Effect of nano$\mathrm{SiO}_{2}$ particles on properties of cement mortar applicable for ferrocement elements", concrete research letter, Vol. (2), No. (1), March, pp: 167-180, (2011).

[2] Bjornstrom J., Martinelli A., Matic A., Borjesson L. and I. Panas, "Accelerating effects of colloidal nano silica for beneficial calcium silicate hydrate formation in cement", Chemical Physics Letters, Vol. (392), pp: 242248 (2004).

[3] A.M. Said, M.S. Zeidan a, M.T. Bassuoni b, Y. Tian, "Properties of concrete incorporating nano silica", Construction and Building Materials, Vol. (36), pp: 838-844, (2012).

[4] Sayed Abd EL-Baky, Sameh Yehia, Ibrahim S. Khalil, "Influence of nano silica addition on properties of fresh and hardened cement mortar", Nano Con, ((16-18)-Oct-2013), Brno, Czech Republic, EU. pp: 1-6, (2013).

[5] B. Kartikeyan, K. Sumanth, G. Harshavardhan, A. Rajasekharareddy, G. Dhinakaran, "Microstructure analysis and Strength properties of concrete with Nano SiO2", International Journal of Chem. Tech. Research, Vol. (6), No. (5), pp: 3004-3013, (Aug-Sep), (2014).

[6] Hui Li, Hui-gang Xiao, Jie Yuan, Jinping Ou, "Microstructure of cement mortar with nano particles", Composites: Part B, Vol. (35), pp: 185-189, (2004).
[7] Behrooz Shirgir, Abolfazl Hassani, Ahmad Khodadadi, "Experimental study on permeability and mechanical properties of nano modified porous concrete", The Transportation Research Record Journal, Vol. (2240), No. (1), pp: 30-35, (2011).

[8] A.Boshehrian and P.Hosseini, "Effect of nano$\mathrm{SiO} 2$ particles on properties of cement mortar applicable for ferrocement elements", ISSR Journals www.crl.issres.net, Vol. (2), No. (1), March, (2011).

[9] A. H. Shekari, M.S. Razzaghi, "Influence of nano particles on durability and mechanical properties of high performance concrete", Procedia Engineering, Vol. (14), pp: 30363041, (2011).

[10] Ali Heidari, Davoud Tavakoli, "A study of the mechanical properties of ground ceramic powder concrete incorporating nano- $\mathrm{SiO}_{2}$ particles", Construction and Building Materials, Vol. (38), pp: 255-264, (2013).

[11]G. Quercia, P. Spiesz, G. Hüsken, H.J.H. Brouwers, "SCC modification by use of amorphous nano silica", Cement \& Concrete Composites, Vol. (45), pp: 69-81, (2014).

[12] A. Heidari, F. Ghaffari and H. Ahmadvand, "Properties of self compacting concrete incorporating alginate and nano silica", Asian journal of civil engineering (BHRC), Vol. (16), No. (1), pp: 1-11, (2015). 


\title{
دراسة الخصائص لمونة الاسمنت باضافة مواد بوزلانية نانوية
}

\author{
فاضل عبد رسن** ليث قيس عباس

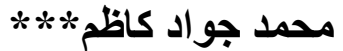

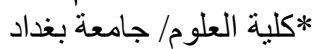

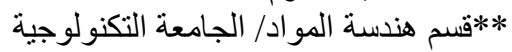

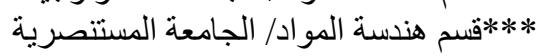

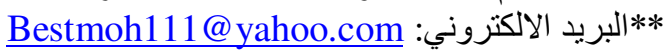

moh_materials@yahoo.com:البريد الالكتروني:**** الاكتي:

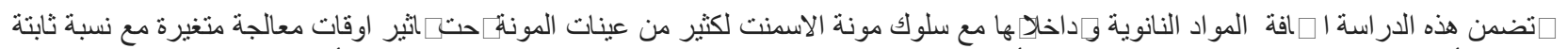

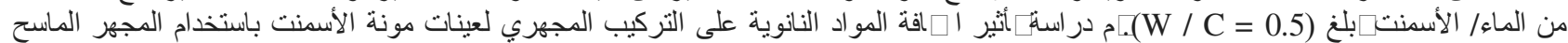

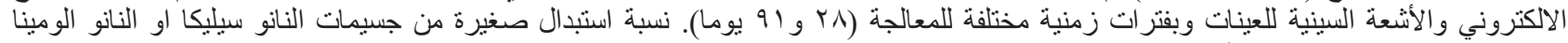

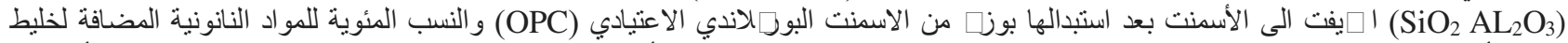

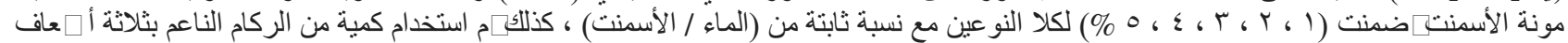

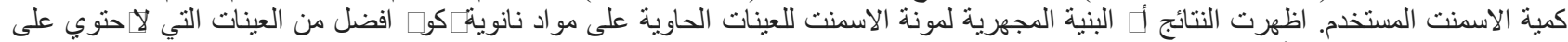

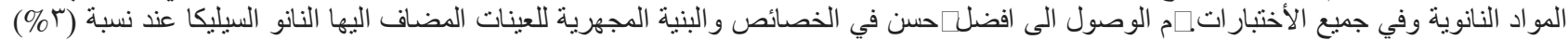

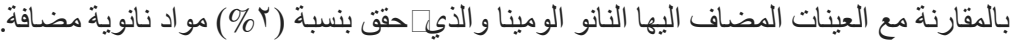

